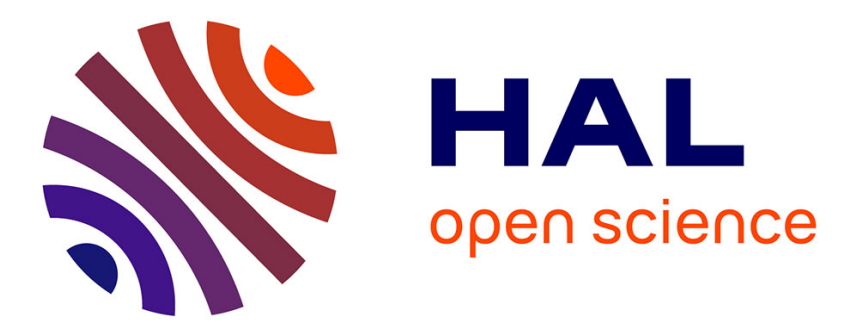

\title{
QUANTITATIVE EVALUATION OF RECOMBINATION ACTIVITY OF DISLOCATIONS BY COMBINED SEM-CL/EBIC
}

J. Schreiber, S. Hildebrandt

\section{- To cite this version:}

J. Schreiber, S. Hildebrandt. QUANTITATIVE EVALUATION OF RECOMBINATION ACTIVITY OF DISLOCATIONS BY COMBINED SEM-CL/EBIC. Journal de Physique IV Proceedings, 1991, 01 (C6), pp.C6-15-C6-19. 10.1051/jp4:1991602 . jpa-00250674

HAL Id: jpa-00250674 https://hal.science/jpa-00250674

Submitted on 1 Jan 1991

HAL is a multi-disciplinary open access archive for the deposit and dissemination of scientific research documents, whether they are published or not. The documents may come from teaching and research institutions in France or abroad, or from public or private research centers.
L'archive ouverte pluridisciplinaire HAL, est destinée au dépôt et à la diffusion de documents scientifiques de niveau recherche, publiés ou non, émanant des établissements d'enseignement et de recherche français ou étrangers, des laboratoires publics ou privés. 


\title{
QUANTITATIVE EVALUATION OF RECOMBINATION ACTIVITY OF DISLOCATIONS BY COMBINED SEM-CL/EBIC
}

\author{
J. SCHREIBER and S. HILDEBRANDT \\ Martin-Luther-Universität Halle-Wittenberg, Fachbereich Physik, Friedemann-Bach-Platz \\ 6, D-4020 Halle (Saale), Germany
}

\begin{abstract}
The methodology of quantitative SEM-CL/EBIC investigations for the evaluation of the recombination defect strength of individual dislocations in crystalline semiconductor samples is presented. The interpretation of the experiments is performed by using a unified theoretical description of $\mathrm{CL}$ and EBIC matrix signals inclusive of the defect contrasts. Full analysis of SEM-CL/EBIC studies on a semiconductor sample with surface Schottky barrier is discussed. The effective defect strength values corresponding to induced non-radiative recombination of dislocations in GaAs, GaAsP, GaP are deduced.
\end{abstract}

\section{1.- Introduction}

An enhanced excess carrier recombination rate at dislocations in crystalline semiconductor samples results in a pronounced SEM-CL and SEM-EBIC defect contrast. Because of the same basic mechanism for defect contrast formation in CL and EBIC mode the conception of combined SEM-CL/EBIC investigations provides an adequate method for quantitative examinations of the microscopic electrical and optical properties at an identical dislocation. In order to deduce quantitative information on the defect induced recombination process a theoretical model for the interpretation of CL as well as EBIC data is necessary. In the defect contrast theory $[1,2]$ the recombination activity of the dislocations is defined by the quantity "defect strength" which can have different meaning in the case of the CL and EBIC contrast of the defect.

Obviously the SEM-EBIC technique is widely used to measure electrical effects at dislocations in $\mathrm{Si}$ and III-V or II-VI semiconductors $[3,4,5]$. Only in the recent years the SEM-CL mode became interesting in connection with studies of recombination induced optical properties of dislocations in optoelectronic materials [5,6]. First papers about the application of SEM-CL/EBIC $[7,8,9]$ have been concerned with the relation between the $\mathrm{CL}$ and EBIC contrast at identical defects in conjunction with the geometrical defect configuration.

In our paper we report on quantitative experimental studies of the recombination active defect strength of dislocations in the III-V semiconductors GaAs, GaAsP, GaP. We investigated surface parallel dislocation lines by means of beam voltage dependent $C L$ and EBIC contrast profile measurements.

\section{2.- Physical fundamentals of SEM-CL/EBIC defect studies}

Both CL and EBIC signal result from diffusion and recombination of the electron hole pairs generated by the impinging electron probe within the generation volume.

For the combined CL/EBIC studies it is appropriate to use the unified description of the CL and EBIC 
quantities given in [10].

The beam voltage dependent matrix signals $\mathrm{I}_{0}{ }^{\mathrm{EBIC}}\left(\mathrm{U}_{\mathrm{b}}\right)$ and $\mathrm{I}_{0}{ }^{\mathrm{CL}}\left(\mathrm{U}_{\mathrm{b}}\right.$, hv $)$, are obtained as

$$
I_{0}^{E B I C}=e G_{0}\left[\Phi\left(0, z_{m}, z_{m}+z_{d}\right)+\Phi\left(1 / L, z_{m}+z_{d}, \infty\right)\right]
$$

for the surface Schottky barrier configuration $\left(\mathrm{U}_{\mathrm{b}}\right.$ - acceleration beam voltage, e - elementary charge, $G_{0}$ - total generation rate, $L$ - minority carrier diffusion length, $z_{m}$ - metal layer thickness, $z_{d}$ depletion layer thickness, hv - photon energy) and

$$
I_{0}^{C L}=2 \pi G_{0} \frac{\tau}{\tau_{r}} \int_{\cos \theta_{c}}^{1} d(\cos \theta) F\left(\frac{\alpha(h v)}{\cos \theta}\right)
$$

Thereby,

$$
F(\hat{\alpha})=\frac{e^{-\hat{\alpha} z_{T}}}{1-\hat{\alpha}^{2} L^{2}}\left[\Phi\left(\hat{\alpha}, z_{, \infty}\right)-\frac{\hat{\alpha} L+S}{1+S} \Phi\left(1 / L, z_{T}, \infty\right)\right]
$$

with $\tau, \tau_{r}$ - total and radiative lifetime, respectively, $\alpha$ - optical absorption coefficient, $\hat{\boldsymbol{\alpha}}=$ $\alpha(h v) / \cos \theta, z_{T}$ - dead layer thickness, $S$ - reduced surface recombination velocity, $\theta_{c}$ - angle of total reflection.

In (1) and (3) the universal function

$$
\Phi\left(x, z_{1}, z_{2}\right)=\int_{z_{1}}^{z_{2}} d z g_{z}(z) e^{-x\left(z-z_{1}\right)}
$$

describes electrical and optical loss and contains the excess carrier generation distribution $\mathrm{g}_{\mathrm{z}}(\mathrm{z})$.

It is useful to analyse the experimental results by fitting the theoretical beam voltage dependent EBIC and $\mathrm{CL}$ matrix signals which yield the sample parameters, in particular, the diffusion length $\mathrm{L}$, optical absorption coefficient $\alpha(h v)$ as well as the values of $S, z_{m}, z_{d}, z_{T}$.

Following the applied defect model $[11,12]$ the EBIC as well as the CL defect contrast can be calculated in analytical form. The EBIC contrast is

$$
C^{E B I C}=-\frac{\tau / \tau^{\prime}-1}{\tau I_{0}^{E B I C}} \int_{\mathfrak{Q}_{v}} d r q(r) j_{E B I C}(\mathrm{z})
$$

It is noteworthy that the theoretical CL defect contrast consists of two parts

$$
C^{C L}=\frac{1}{\tau_{r} I_{0}^{C L}} \int_{\cos \theta_{c}}^{1} d(\cos \theta)\left[-\left(\frac{\tau}{\tau^{\prime}}-1\right) \int_{a_{r}} d r q(r) j_{C L}(z)+\left(\frac{\tau_{r}}{\tau_{r}^{\prime}}-1\right) \int_{a_{V}^{r}} d r q(r) e^{-\hat{\alpha} z}\right]
$$

$\left(\tau^{\prime}, \tau_{r}{ }^{\prime}\right.$ - lifetimes in the defect regions $\Omega_{v}, \Omega_{v}^{r}, q(r)$ - excess minority carrier density, $j_{\mathrm{EBIC}}, \mathrm{j}_{\mathrm{CL}}$ - matrix signals for unit point source excitation at depth $\mathrm{z}$ ) where the first term results from a change in the total lifetimes $t / t$ ' like the EBIC contrast, too, but the second term appears due to a modification in the radiative lifetime $\tau_{r} / \tau_{r}$. The defect strength quantities $\lambda_{e}, \lambda_{r}^{C L}$ are introduced into the considerations by the relations 


$$
\begin{gathered}
C^{E B I C}\left(\xi, U_{b}\right)=\lambda_{e} \cdot c_{E B I C}^{*}\left(\xi, U_{b}, z_{V}, r_{v r} L\right) \\
C^{C L}\left(\xi, U_{b}\right)=\lambda_{e} \cdot c_{C L, e}^{*}\left(\xi, U_{b}, z_{v}, r_{v}, L, \alpha, S\right)+\lambda_{r}^{C L} \cdot c_{C L, r}^{*}\left(\xi, U_{b}, z_{v}, r_{V}^{r}, L, \alpha, S\right)
\end{gathered}
$$

with $\xi$ - electron beam position, $z_{v}$ - defect depth position, $r_{v}, r_{v}^{r}$ - defect radii.

In the first-order approximation one obtains

$$
\lambda_{e}=\pi\left(\frac{r_{V}}{L}\right)^{2}\left(\frac{\tau}{\tau^{\prime}}-1\right) ; \quad \lambda_{r}^{C L}=\pi\left(\frac{r_{V}^{\prime}}{L}\right)^{2}\left(\frac{\tau_{r}}{\tau_{r}^{\prime}}-1\right)
$$

The pure contrast profile functions $\mathrm{c}^{\star}$ can be calculated for the actual experimental situation using the relevant values of $L, \alpha, S, z_{y} \ldots$ An improvement of the theoretical description of the defect contrast is achieved by introduction of the contrast profile area $[13,14]$

$$
A=\int d \xi C(\xi)
$$

The advantage of the combined CL/EBIC experiments and their interpretation on base of the quantitative theoretical description is the ability to yield reliable values for the defect strength utilizing the actual data from the crystal matrix and defect geometry using $\mathrm{z}_{\mathrm{v}}$ values concluded from the experiments. According to $[9,12]$, at any beam voltage the dislocation depth $z_{v}$ can be calculated from the EBIC to CL contrast ratio conveniently since in the case of $\lambda_{r}^{C L}=0$ this ratio is independent of the defect strength:

$$
\frac{C^{E R I C}}{C^{C L}}\left(z_{v}\right)=\frac{\frac{I_{0}^{C L}}{\tau / \tau_{r}} j_{E B I C}\left(z_{v}\right)}{I_{0}^{E B I C} j_{C L}\left(z_{v}\right)}
$$

The analysis of experimentally determined FBIC to CL defect contrast ratios provides very accurate data on the defect depth position. The geometrical information follows from the different contrast formation in CL and EBIC mode due to spatial photon and charge carrier spreading and loss processes.

\section{3.- Experimental results and discussion.}

The experimental technique applied to SEM-CL/EBIC studies carried out here was already described in [11]. Semiconductor samples used were n-doped bulk GaAs and epitaxial layers of GaAsP and GaP with crystallographically defined line dislocations.

The first experimental finding in the SEM-CL/EBIC is that the dislocations exhibit corresponding defect contrasts in the $\mathrm{CL}$ and EBIC mode. The beam voltage dependent contrast profile measurements prove different $\mathrm{CL}$ and EBIC contrast values and various contrast behaviour concerning the beam voltage dependence at the identical defect.

In Fig. 1 the EBIC to CL contrast ratio for two dislocation lines in a GaP sample in surface Schottky barrier configuration is represented. The functional dependence of the contrast ratio on beam voltage gives evidence for the correlation between the $C L$ and EBIC defect contrast.

From the slope of the curves the depth positions $z_{v}$ of the dislocation lines under consideration are derived. The depths of dislocation (1) and (2) amount to $z_{v}=(1.04 \pm 0.02) \mu \mathrm{m}$ and $z_{v}=(1.89 \pm$ 0.05) $\mu \mathrm{m}$, respectively. The errors given are obtained from the non-linear regression. 
Fig. 1. EBIC to CL defect contrast ratio as a function of beam voltage determined for two surface-parallel dislocation lines in a $\mathrm{n}$-GaP sample with surface Schottky barrier $\left(z_{m}=\right.$ $\left.0.045 \mu \mathrm{m}, \mathrm{z}_{\mathrm{d}}=0.32 \mu \mathrm{m}\right)$. The depth positions of the dislocations were concluded to $\mathrm{z}_{\mathrm{v} 1}=(1.04 \pm$ 0.02) $\mu \mathrm{m}, \mathrm{z}_{\mathrm{v} 2}=(1.89 \pm 0.05) \mu \mathrm{m}$ using material parameter values $L=$ $0.90 \mu \mathrm{m}, \alpha=0.27 \mu \mathrm{m}^{-1}$

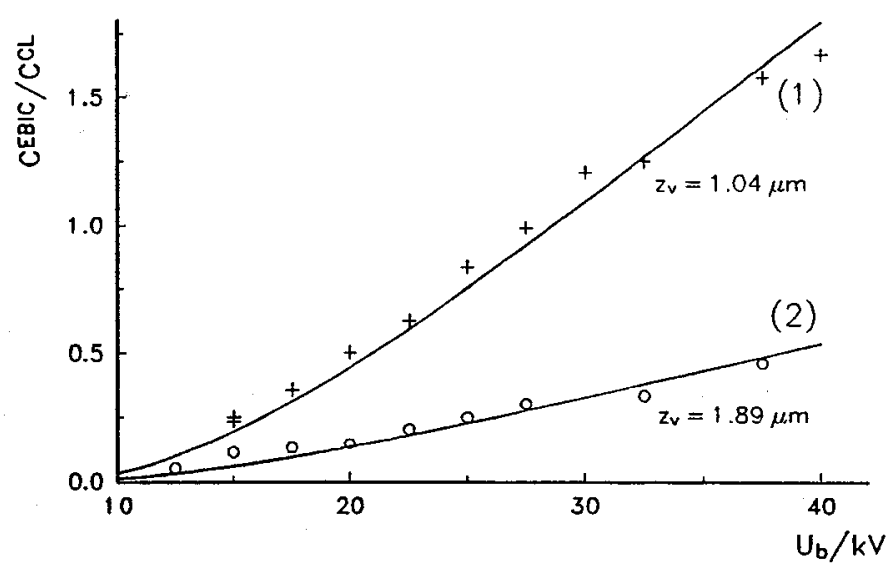

In Fig. 2 the dependence of EBIC and CL defect contrast profile areas on beam voltage defined by (9) is shown. The experimental points are fitted by the theoretical relations for $A^{\text {EBIC }}$ and $A^{\text {CL }}$ calculated utilizing the $z_{\mathrm{v}}$ values and actual sample parameters determined during the experimental procedure. From the fitting of $A^{\mathrm{EBIC}}$ and $\mathrm{A}^{\mathrm{CL}}$ data, respectively, the $\mathrm{CL}$ and EBIC defect strength values are derived. Assuming radiationless recombination at the defect in the CL and EBIC contrast formulas only the defect strength $\lambda_{\mathrm{e}}$ occurs. This is confirmed by the experimentally deduced CL and EBIC defect strength values of same amount $\left(\lambda_{e}=2.45\right)$.

Fig. 2. EBIC and CL defect contrast profile area of dislocation (1) as a function of beam voltage derived from the contrast profile measurements on the GaP sample as in Fig. 1. The effective $\mathrm{CL}$ and EBIC defect strength value could be evaluated. $\lambda_{e}(C L)=$ $\lambda_{e}(E B I C)=2.45$ was obtained using the parameter values given in the caption of Fig. 1

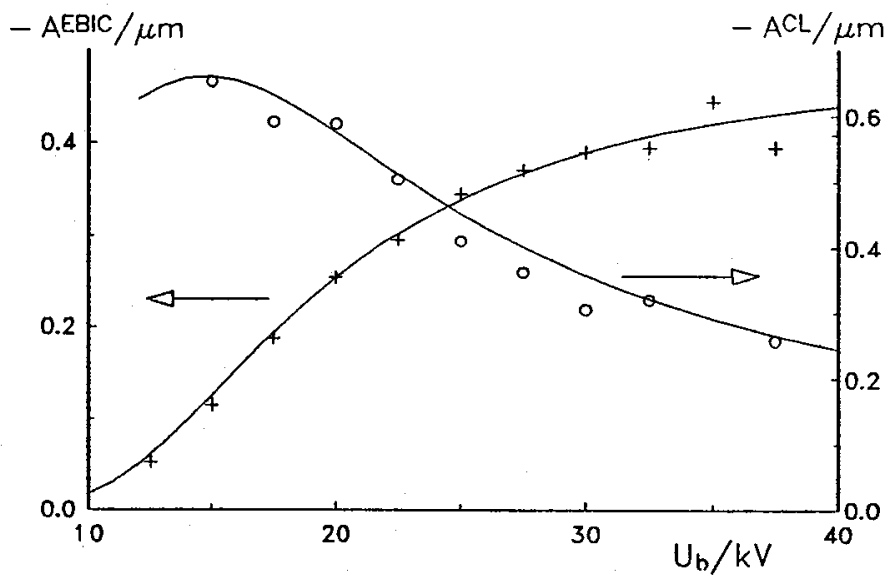

Experimentally determined defect strength values of line dislocations are compiled in Table 1. A screw. type glide dislocation was investigated in GaAs. All other defects considered were edge type line dislocations in the near surface misfit configuration of GaAsP or GaP epitaxial layers. In the column of the defect strength $\lambda_{e}$ one recognizes a scattering of the values over about one order of magnitude. A better result is obtained by calculating the quantity $\lambda_{e} L^{2}$ in which the influence of the bulk diffusion length $\mathrm{L}$ should be eliminated from the value characterizing the defect recombination activity. Then one finds out that all values of edge type dislocations group above $0.8 \mu \mathrm{m}^{2}$, whereas the screw type glide 
dislocation possesses the lowest value found.

The differences of the recombination activity concluded for the individual dislocations are not explained by the type of dislocation only, but may be probably influenced also by interaction with point defects. The lower value found for the screw dislocation agrees with the assumption of a weaker recombination activity of this defect type.

Tab. 1: Defect strength of dislocations in III-V semiconductors

\begin{tabular}{|c|c|c|c|c|c|}
\hline Material & Defect type & $\mathrm{L} / \mu \mathrm{m}$ & $\mathrm{z}_{\mathrm{v}} / \mu \mathrm{m}$ & $\lambda_{e}$ & $\lambda_{e} \cdot \mathrm{L}^{2} / \mu \mathrm{m}^{2}$ \\
\hline $\begin{array}{l}\text { GaAs:Si } \\
\mathrm{n}=9 \cdot 10^{17} \mathrm{~cm}^{-3}\end{array}$ & $\begin{array}{l}\text { screw type } \\
\text { glide dislocation }\end{array}$ & 0.75 & 1.0 & 0.67 & 0.38 \\
\hline $\begin{array}{l}\text { GaAsP } \\
(x=0.38)\end{array}$ & $\begin{array}{l}\text { edge type } \\
\text { misfit }\end{array}$ & 1.2 & 1.9 & 1.09 & 1.56 \\
\hline $\mathrm{n}=3 \cdot 10^{16} \mathrm{~cm}^{-3}$ & $\begin{array}{l}\text { dislocation } \\
\left(60^{\circ} / 90^{\circ}\right)\end{array}$ & 4.0 & 1.4 & 0.08 & 1.28 \\
\hline$"$ & $"$ & 1.2 & 0.7 & 0.65 & 0.91 \\
\hline$"$ & $"$ & 1.2 & 0.65 & 0.59 & 0.82 \\
\hline $\begin{array}{l}\mathrm{GaP} \\
\mathrm{n}=7 \cdot 10^{16} \mathrm{~cm}^{-3}\end{array}$ & $"$ & 0.89 & 1.05 & 2.45 & 1.94 \\
\hline
\end{tabular}

\section{Acknowlegment.}

The authors wish to thank $H$. Mähl for the useful cooperation and technical assistance in the performance of the SEM experiments and the sample preparation.

\section{References.}

[1] DONOLATO, C, phys. stat. sol. (a) 66 (1981) 445

[2] PASEMANN, L, Ultramicroscopy 6 (1981) 237

[3] HOLT, D B, JOY, D C, SEM Microcharacterization of Semiconductors, Academic Press, New York 1989

[4] ALEXANDER, H, DIETRICH, S, HÜHNE, M, KOLBE, M, WEBER, G, phys. stat. sol. (a) 117 (1990) 417

[5] SCHREIBER, J, HERGERT, W, HILDEBRANDT, S, Appl. Surf. Sci. 50 (1991) 181

[6] YACOBI, B G, HOLT, D B, Cathodoluminescence of Inorganic Solids, Plenum Press, New York, London 1990

[7] JAKUBOWICZ, A, BODE, M, HABERMEIER, H-U, Inst. Phys. Conf. Ser. 87 (1987) 763

[8] ECKSTEIN, M, JAKUBOWICZ, A, BODE, M, HABERMEIER, H-U, Inst. Phys. Conf. Ser. 100 (1989) 755

[9] PASEMANN, L, HERGERT, W, Ultramicroscopy 19 (1986) 15

[10] HERGERT, W, HILDEBRANDT, S, PASEMANN, L, phys. stat. sol. (a) 102 (1987) 819

[11] SCHREIBER, J, HERGERT, W, Inst. Phys. Conf. Ser. 104 (1989) 97

[12] HERGERT, W, Thesis B, Halle 1988

[13] DONOLATO, C, BIANCONI, M, phys. stat. sol. (a) 102 (1987) K 7

[14] HILDEBRANDT, S, HERGERT, W, phys. stat. sol. (a) 119 (1990) 689 